\title{
Calcium-sensing Receptor Mutations in Familial Benign Hypercalcemia and Neonatal Hyperparathyroidism
}

\author{
S. H. S. Pearce, ${ }^{\star}$ D. Trump, ${ }^{\star}$ C. Wooding, ${ }^{\star}$ G. M. Besser, ${ }^{\ddagger}$ S. L. Chew, ${ }^{\ddagger}$ D. B. Grant, ${ }^{5}$ D. A. Heath, ${ }^{\prime \prime}$ I. A. Hughes, ${ }^{1}$ \\ C. R. Paterson, ${ }^{* \star}$ M. P. Whyte, ${ }^{\#}$ and R. V. Thakker* \\ ${ }^{*}$ MRC Molecular Endocrinology Group, Royal Postgraduate Medical School, London, W12 ONN, United Kingdom; ${ }^{\ddagger}$ Department of \\ Endocrinology, St. Bartholomew's Hospital, London, United Kingdom; ${ }^{8}$ Institute of Child Health, London, United Kingdom; "Department \\ of Medicine, Selly Oak Hospital, Birmingham, United Kingdom; ' Department of Paediatrics, Addenbrookes Hospital, Cambridge, United \\ Kingdom; **Department of Biochemical Medicine, Ninewells Hospital and Medical School, Dundee, United Kingdom; and ${ }^{\ddagger \ddagger}$ Metabolic \\ Research Unit, Shriners Hospital for Crippled Children, St. Louis, Missouri
}

\begin{abstract}
Familial benign hypercalcemia (FBH) and neonatal hyperparathyroidism (NHPT) are disorders of calcium homeostasis that are associated with missense mutations of the calcium-sensing receptor ( $\mathrm{CaR})$. We have undertaken studies to characterize such CaR mutations in FBH and NHPT and to explore methods for their more rapid detection. Nine unrelated kindreds (39 affected, 32 unaffected members) with FBH and three unrelated children with sporadic NHPT were investigated for mutations in the 3,234-bp coding region of the CaR gene by DNA sequencing. Six novel heterozygous (one nonsense and five missense) mutations were identified in six of the nine FBH kindreds, and two de novo heterozygous missense mutations and one homozygous frame-shift mutation were identified in the three children with NHPT. Our results expand the phenotypes associated with CaR mutations to include sporadic NHPT. Singlestranded conformational polymorphism analysis was found to be a sensitive and specific mutational screening method that detected $>85 \%$ of these CaR gene mutations. The single-stranded conformational polymorphism identification of CaR mutations may help in the distinction of FBH from mild primary hyperparathyroidism which can be clinically difficult. Thus, the results of our study will help to supplement the clinical evaluation of some hypercalcemic patients and to elucidate further the structure-function relationships of the CaR. (J. Clin. Invest. 1995. 96:2683-2692.) Key words: cation - $G$ protein - parathyroid - DNA abnormality - mutational screening
\end{abstract}

\section{Introduction}

The human calcium-sensing receptor $(\mathrm{CaR})^{1}$ is a 1,078 -amino acid cell surface protein which is expressed in the parathyroids,

Address correspondence to R.V. Thakker, M.D., F.R.C.P., MRC Molecular Endocrinology Group, Collier Building, Royal Postgraduate Medical School, Du Cane Road, London, W12 0NN, United Kingdom. Phone: 181-7403014; FAX: 181-7498341.

Received for publication 30 May 1995 and accepted in revised form 7 September 1995.

1. Abbreviations used in this paper: $\mathrm{CaR}$, calcium-sensing receptor; FBH, familial benign hypercalcemia; MEN1, multiple endocrine neoplasia type 1; NHPT, neonatal hyperparathyroidism; SSCP, single-stranded conformational polymorphism; SSO, sequence-specific oligonucleotide.

J. Clin. Invest.

(C) The American Society for Clinical Investigation, Inc.

$0021-9738 / 95 / 12 / 2683 / 10 \quad \$ 2.00$

Volume 96, December 1995, 2683-2692 thyroid C cells, and kidney, and is a member of the family of $\mathrm{G}$ protein-coupled receptors $(1,2)$. The CaR gene is located on chromosome $3 q 21-q 24$ and loss of function mutations have been reported in the hypercalcemic disorders of familial benign hypercalcemia (FBH) and neonatal hyperparathyroidism (NHPT) (3-5) and a gain of function mutation has been reported in the hypocalcemic disorder referred to as autosomal dominant hypocalcemia (6). FBH, which is also referred to as familial hypocalciuric hypercalcemia, is an autosomal dominant disorder with a high degree of penetrance, that is characterized by lifelong asymptomatic hypercalcemia in association with an inappropriately low urinary calcium excretion (7-11). A normal circulating parathyroid hormone (PTH) concentration and mild hypermagnesemia are also typically present $(9,11)$. Although most patients with FBH are asymptomatic, chondrocalcinosis and acute pancreatitis have occasionally been observed to occur $(7,8,11)$. In addition, children of consanguineous marriages within FBH kindreds have been observed to have life-threatening hypercalcemia due to severe NHPT (10-14). These children suffer from failure to thrive, dehydration, bony undermineralization, rib cage deformities, multiple fractures, and hypotonia in the first weeks of life and these complications often necessitate urgent parathyroidectomy $(10,12-14)$. These two hypercalcemic disorders may represent the differential effects of gene dosage, as FBH has been reported to be associated with heterozygous mutations in the $\mathrm{CaR}$ gene in nine kindreds whereas NHPT was associated with a homozygous mutation in two of these kindreds $(3,4)$. However, the relationship between NHPT and FBH is often unclear as some patients with NHPT lack a family history of FBH and appear to be sporadic, whereas others may have a milder phenotype with a self-limiting course (11, 14-18). In addition, the clinical importance of FBH lies in its differentiation from primary hyperparathyroidism, and it has been reported that $10 \%$ of patients in whom hypercalcemia failed to respond to parathyroid surgery had FBH $(7-11,14$, 19). The diagnosis of FBH relies on the interpretation of urinary calcium excretion values taken together with a family history of hypercalcemia or failed parathyroid surgery (7-9). However, there may not be a clear distinction between FBH and primary hyperparathyroidism on the basis of urinary calcium excretion alone $(7-9,11,14)$, and in small kindreds a family history may be difficult to elicit. To supplement the clinical evaluation of such patients, we have undertaken studies to characterize the spectrum of $\mathrm{CaR}$ mutations with the aim of facilitating a molecular genetic screening strategy.

\section{Methods}

Patients. Venous blood samples were obtained from 39 affected and 32 unaffected members of nine FBH families (Fig. 1). The clinical 


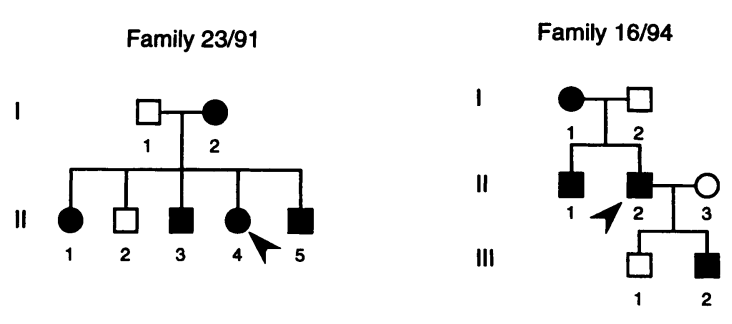

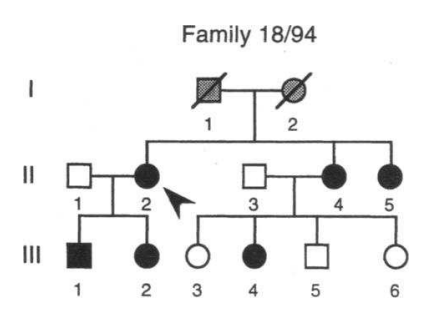

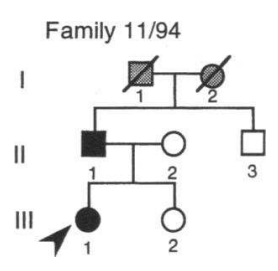

Family 11/91

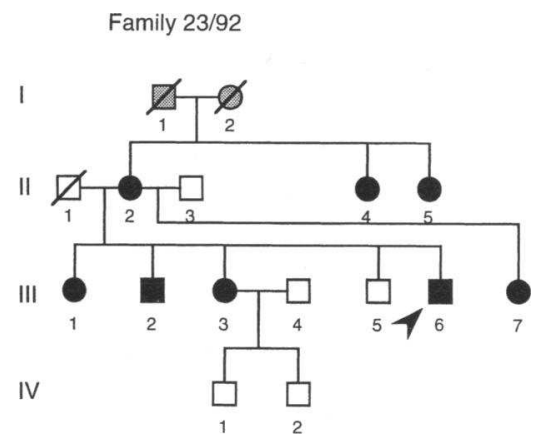

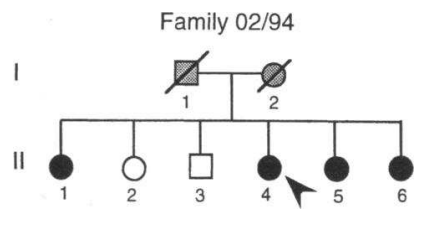

Family $18 / 92$

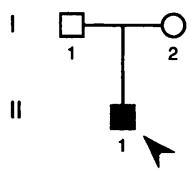

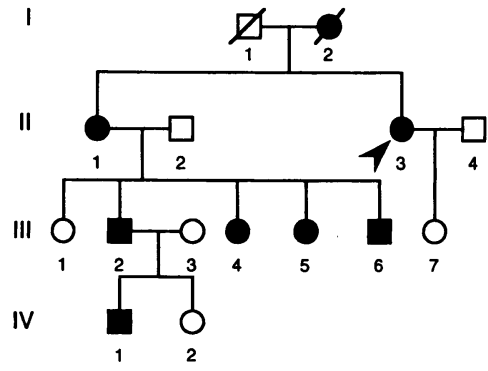

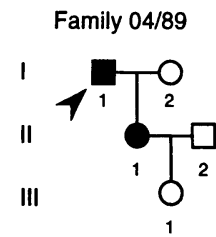

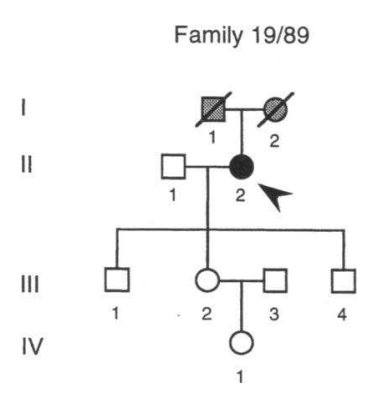

6

Figure 1. The pedigrees of families with FBH and NHPT. Individuals are represented as: affected male, $\mathbf{\square}$; unaffected male, $\square$; affected female, -; unaffected female, $\mathrm{O}$; and of unknown phenotype, $\square$ or $\bigcirc$. Probands are indicated by the arrow. The biochemical details of each proband are shown in Table I and the clinical and biochemical findings in families $11 / 91,18 / 92,11 / 94,23 / 92$, and $08 / 93$ have been reported previously (references $8,17,19,20$, and 22, respectively). Family 02/94 was initially considered to suffer from MEN1 as individual II-6 had hypercalcemia initially detected at the age of $51 \mathrm{yr}$, and then had acromegaly, due to a somatotrophinoma 4 yr later. However, no other member of this kindred had any manifestation of an MEN1 tumor, despite regular screening. In addition, the three individuals II-4, II-5, and II-6 all remained hypercalcemic after parathyroidectomy and all had urinary calcium clearance to creatinine clearance ratios of 0.006 or less, and the diagnosis was revised to FBH. In family $18 / 92$ the father of the proband I-1 with NHPT was normocalcemic but had a low urinary calcium clearance to creatinine clearance ratio of 0.003 . In addition, the proband I-1 (family 18/92) was observed to have a more severe form of NHPT (Table I) when compared with the other two NHPT children II-2 (family 08/93) and II-2 (family 08/94); these phenotypic variations in NHPT correlated with the CaR mutations found in these children. Thus, the severe NHPT of proband I-1 (family 18/92) was associated with a homozygous CaR mutation whereas the milder forms of NHPT in probands II-1 (family 08/93) and II-2 (family 08/94) were associated with de novo heterozygous CaR mutations (Figs. 6 and 7 and Table III).

details of families $11 / 91,11 / 94$, and $23 / 92$ have been reported previously $(9,20,21)$, and the clinical details of the probands from these and other families are summarized in Table I. In addition, persistent hypercalcemia after parathyroid surgery has been observed in individuals II-2 from family 16/94, I-1 and II-1 from family 04/89, III-1 from family $11 / 94$, II-4 and III-4 from family 18/94, II-2 and III-6 from family $23 / 92$, II-3 and III-5 from family $11 / 91$, and II-4, II-5, and II6 from family $02 / 94$ (Fig. 1). Histological examination of the parathyroids revealed either normal parathyroid tissue or chief cell hyperplasia in all cases. Three patients who suffered from NHPT (Table I) but in whose families there was no evidence of hypercalcemia were investigated together with their family members (Fig. 1). All three children with NHPT had presented with neonatal hypercalcemia which was associated with marked bony undermineralization. Parathyroidectomy and histological examination revealed chief cell hyperplasia of all four parathyroid glands in the three NHPT children who all became hypocalcemic and required vitamin D replacement postoperatively; the clinical courses of individual II-1 from family $18 / 92$ and individual II-2 from family $08 / 93$ have been reported previously $(18,22)$. The parents and siblings
(Fig. 1) of the three children with NHPT were normocalcemic (Table I).

DNA hybridization and microsatellite polymorphism analysis. DNA from leukocytes, fixed paraffin-embedded parathyroid, and animal tissues was prepared by standard methods $(23,24)$, and DNA from semen was prepared by washing twice with PBS, lysing with $0.2 \mathrm{M}$ potassium hydroxide and $50 \mathrm{mM} \mathrm{DTT} \mathrm{at} 65^{\circ} \mathrm{C}$ for $10 \mathrm{~min}$, and then neutralizing to $\mathrm{pH} 7.0$ with $\mathrm{HCl}$. Intragenic DNA probes of $900 \mathrm{bp}$ and $1.1 \mathrm{kbp}$ from exons 4 and 7, respectively, of the $\mathrm{CaR}$ gene were obtained by PCR and primer pairs 3AF and 3BR, and 7GF and 6BR (Fig. 2). Restriction fragment length polymorphisms and microsatellite polymorphisms were detected using previously described methods (23-26). Six polymorphic microsatellite loci (D3S47, RHO, ACPP, D3S196, D3S1303, and D3S1267) from 3q21-3q24 $(25,26)$ were used in segregation studies for the CaR locus, and five loci (D3S1303, D3S1267, D11S533, D13S260, and Rb1.20), each with eight or more alleles and a heterozygosity $>70 \%$, were used to exclude nonpaternity, as described previously $(25,26)$.

DNA sequence analysis of the CaR gene. 12 pairs of primers were 


\begin{tabular}{|c|c|c|c|c|c|c|c|}
\hline Family & Proband & Mean serum calcium & Serum phosphate & Serum magnesium & Plasma PTH & $\begin{array}{l}\text { Urinary calcium } \\
\text { clearance to } \\
\text { creatinine } \\
\text { clearance ratio }\end{array}$ & $\begin{array}{l}\text { Mean family* } \\
\text { serum calcium }\end{array}$ \\
\hline Normal ranges & & $\begin{array}{l}\text { (2.15-2.65 } \\
\text { mmoИiter) }\end{array}$ & $\begin{array}{c}(0.8-1.4 \\
\text { mmolhiter })\end{array}$ & $\begin{array}{c}(0.8-1.0 \\
\text { mmo-hiter })\end{array}$ & (assay range) & $(>0.01)$ & $\begin{array}{l}(2.15-2.65 \\
\text { mmolniter) }\end{array}$ \\
\hline \multicolumn{8}{|l|}{ FBH kindreds } \\
\hline $02 / 94$ & II-4 & 2.85 & 0.98 & 0.94 & $185 \mathrm{pg} / \mathrm{ml}(<120)$ & 0.005 & 2.75 \\
\hline $04 / 89$ & I-1 & 2.80 & 0.77 & 0.87 & $4.6 \mathrm{pmol} /$ liter $(1-5.3)$ & 0.01 & 2.82 \\
\hline $11 / 91$ & II-3 & 2.76 & 0.74 & - & $3.0 \mathrm{pmol} / \mathrm{liter}(1.2-7.6)$ & 0.013 & 2.72 \\
\hline $11 / 94$ & III-1 & 2.90 & 0.98 & 0.99 & $0.6 \mathrm{ng} / \mathrm{ml}(<0.2)$ & $\mathrm{NA}^{\ddagger}$ & 2.83 \\
\hline $16 / 94$ & II-2 & 2.75 & 0.75 & - & $3.2 \mathrm{pmol} / \mathrm{liter}(0.9-5.4)$ & 0.006 & 2.74 \\
\hline $18 / 94$ & II-2 & 2.98 & 0.80 & - & $4.2 \mathrm{pmol} /$ liter $(1-5.3)$ & 0.0075 & 2.96 \\
\hline $19 / 89$ & II-2 & 2.79 & 0.82 & 0.90 & $3.2 \mathrm{pmol} /$ liter $(1-5.3)$ & 0.008 & - \\
\hline 23/92 & III-6 & 2.77 & 0.74 & 0.81 & $0.2 \mathrm{ng} / \mathrm{ml}(<0.2)$ & 0.004 & 2.79 \\
\hline \multirow[t]{2}{*}{$23 / 91$} & II-4 & 2.83 & 0.99 & 0.51 & $5.2 \mathrm{pmol} /$ liter $(1-5.0)$ & $0.0055^{8}$ & 2.81 \\
\hline & & & & & & \multicolumn{2}{|c|}{ Parental serum calcium (mmol/iter) } \\
\hline NHPT probands & & & & & & Paternal & Maternal \\
\hline 08/93 & II-2 & 2.94 & 0.90 & 0.92 & $170 \mathrm{pg} / \mathrm{ml}(<120)$ & 2.40 & 2.40 \\
\hline $08 / 94$ & II-2 & 2.82 & 1.26 & - & $138 \mathrm{meq} / \mathrm{ml}(4-9)$ & 2.38 & 2.42 \\
\hline $18 / 92$ & II-1 & 6.53 & 0.87 & 0.89 & $78 \mathrm{pmol} /$ iter $(1.1-6.8)$ & 2.52 & 2.50 \\
\hline
\end{tabular}

* Mean values of affected family members are stated. ${ }^{\ddagger}$ Preparathyroidectomy values not available. ${ }^{8}$ Proband II-4 underwent parathyroidectomy before evaluation and the calcium/creatinine clearance shown is that of her affected brother II-5.

used for the PCR amplification of the six coding exons of the CaR gene (Fig. 2) and 9 of the 12 splice sites from each proband (Fig. 1) and an unrelated normocalcemic individual. The DNA sequences of 17 primers (Fig. 2) have been reported (3) and the sequences of four of the seven novel primers derived from our sequence analysis of the $\mathrm{CaR}$ gene (Reference 2, GenBank accession No. X81086) are shown in Table II. The DNA sequences of the three remaining primers were: 4DF5'CGACTTCAGTGAACTCATCTCCCAG 3'; 4DR-5'CCTTTTGCACCTTCTTGGAGGTGGC 3 '; and 4EF-5'ATCCCAGGAAGTCTGTCCACAATGG $3^{\prime}$. The amplification reactions used $100 \mathrm{ng}$ of template DNA, 50 pmol of each primer, $200 \mu \mathrm{M}$ dNTPs, $1 \mathrm{mM}$ magnesium chloride, $50 \mathrm{mM}$ potassium chloride, $10 \mathrm{mM}$ Tris- $\mathrm{HCl}(\mathrm{pH} 8.3$ ), and 1 U Taq DNA polymerase (GIBCO BRL, Gaithersburg, MD) in a final volume of $50 \mu \mathrm{l}$. After an initial denaturation at $95^{\circ} \mathrm{C}$ for $5 \mathrm{~min}, 40$ cycles of PCR amplification were performed with each cycle consisting of $30 \mathrm{~s}$ at $94^{\circ} \mathrm{C}$ for denaturation, $30 \mathrm{~s}$ at $65^{\circ} \mathrm{C}$ for primer annealing, and $30 \mathrm{~s}$ at $72^{\circ} \mathrm{C}$ for DNA extension. After 40 cycles a final DNA extension step at $72^{\circ} \mathrm{C}$ for $5 \mathrm{~min}$ was performed. $20 \mu \mathrm{l}$ of the PCR product was then electrophoresed on a $2 \%$ agarose gel, purified by spinning through siliconized glass wool, and the DNA sequences of both strands were determined by Taq polymerase cycle sequencing with fluorochromelabeled dideoxy-terminators which were resolved on a semiautomated

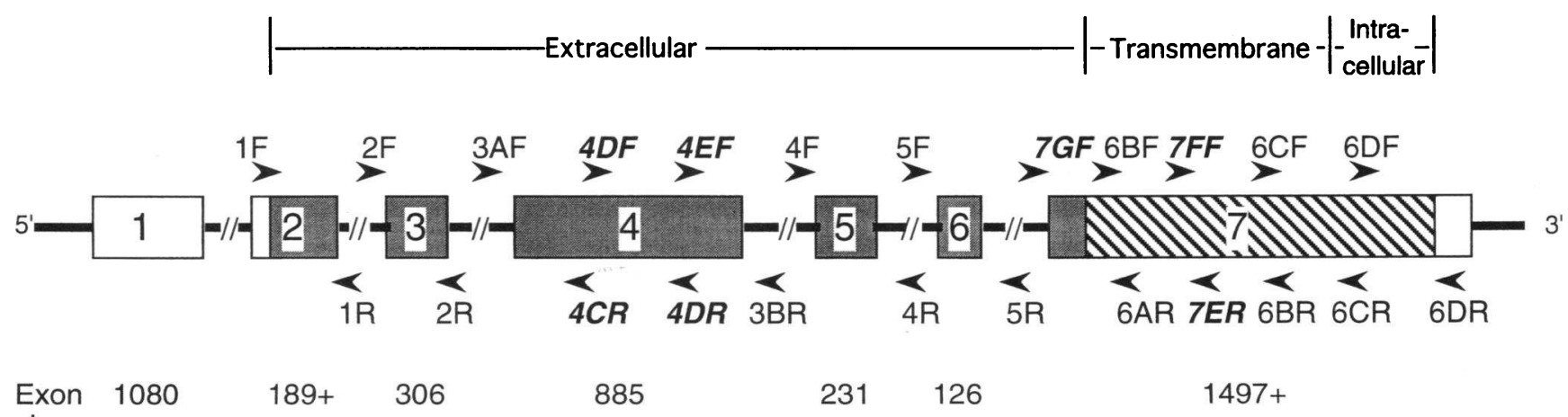

size

(bp)

Figure 2. Schematic representation of the genomic structure and position of primer pairs in the CaR gene. The human $\mathrm{CaR}$ gene spans $>45 \mathrm{~kb}$ of genomic DNA (29) and is organized into seven exons, whose sizes are indicated, and six introns $(1,2,29)$. The gene encodes a seventransmembrane domain protein that is typical of a $G$ protein-coupled receptor (1). Exons 2 to the $5^{\prime}$ end of exon 7 encode the 612 amino acids of the extracellular, presumably ligand-binding domain, $\square$; exon 7 encodes the 250 amino acids of the transmembrane domain and loops together with the 216-amino acid intracellular tail, $\square$; and exon 1 and the $3^{\prime}$ end of exon 7 are untranslated, $\square$; 12 pairs of primers (shown as arrows) were designed to amplify exons 2 to 7 , and 9 of the 12 intron/exon boundaries; the 7 novel primers are indicated in bold and the DNA sequences of the remaining 17 primers have been reported previously (3). 
Table II. Conditions for SSCP Analysis of the CaR Gene

\begin{tabular}{|c|c|c|c|c|c|c|c|}
\hline Exon & & Primer sequence* $\left(5^{\prime} \rightarrow 3^{\prime}\right)$ & $\begin{array}{c}\text { Product } \\
\text { size }\end{array}$ & Temperature & $\begin{array}{l}\text { Voltage } \\
\text { time }\end{array}$ & $\begin{array}{c}\text { Mutations } \\
\text { present }\end{array}$ & $\begin{array}{l}\text { Mutations } \\
\text { detected }^{\ddagger}\end{array}$ \\
\hline \multirow[t]{2}{*}{2} & $1 \mathrm{~F}$ & TCCCTTGCCCTGGAGAGACGGCAGA & \multirow[t]{2}{*}{$250 \mathrm{bp}$} & \multirow[t]{2}{*}{$10^{\circ} \mathrm{C}$} & \multirow[t]{2}{*}{$210 \mathrm{Vh}$} & \multirow[t]{2}{*}{ P55L } & \multirow[t]{2}{*}{$\mathrm{Y}$} \\
\hline & 1R & AGAGAAGAGATTGGCAGATTAGGCC & & & & & \\
\hline \multirow[t]{2}{*}{4} & $3 \mathrm{AF}$ & ACTCATTCACCATGTTCTTGGTTCT & \multirow[t]{2}{*}{$335 \mathrm{bp}$} & $10^{\circ} \mathrm{C}$ & $300 \mathrm{Vh}$ & Y218S & $\mathrm{Y}^{\S}$ \\
\hline & $4 \mathrm{CR}$ & CTTTGGCCGTGGAATTTTGAATCACC & & $10^{\circ} \mathrm{C}$ & $250 \mathrm{Vh}$ & R227L & $\mathrm{Y}$ \\
\hline \multirow[t]{2}{*}{7} & $7 \mathrm{GF}$ & AGTCTGTGCCACACAATAACTCACTC & \multirow[t]{2}{*}{$272 \mathrm{bp}$} & $10^{\circ} \mathrm{C}$ & $210 \mathrm{Vh}$ & C582Y & $\mathrm{Y}$ \\
\hline & 6AR & GGTAGGAGAGCTCTCGGTTGGTGGC & & $10^{\circ} \mathrm{C}$ & $210 \mathrm{Vh}$ & S607stop & $\mathrm{Y}$ \\
\hline \multirow[t]{3}{*}{7} & $6 \mathrm{BF}$ & TTCCGCAACACACCCATTGTCAAGG & \multirow[t]{3}{*}{$423 \mathrm{bp}$} & $15^{\circ} \mathrm{C}$ & $350 \mathrm{Vh}$ & G670R & $\mathrm{Y}$ \\
\hline & 7ER & CGATCAGGAAGCCCAGGGCCATGAG & & $15^{\circ} \mathrm{C}$ & $350 \mathrm{Vh}$ & $\mathrm{R} 680 \mathrm{C}$ & $\mathrm{Y}$ \\
\hline & & & & $15^{\circ} \mathrm{C}$ & $350 \mathrm{Vh}$ & P747fs & Y \\
\hline \multirow[t]{2}{*}{7} & 7FF & GGAGGATGAGATCATCTTCATCACG & \multirow{2}{*}{$457 \mathrm{bp}$} & \multirow{2}{*}{$\begin{array}{c}10,15 \text {, and } \\
20^{\circ} \mathrm{C}\end{array}$} & \multirow[t]{2}{*}{$350 \mathrm{Vh}$} & \multirow[t]{2}{*}{ V8.17I } & \multirow[t]{2}{*}{$\mathrm{N}$} \\
\hline & 6BR & GGATCCCGTGGAGCCTCCAAGGCTG & & & & & \\
\hline
\end{tabular}

* Primers as referred to in Fig. 2; primers $1 \mathrm{~F}, 1 \mathrm{R}, 3 \mathrm{AF}, 6 \mathrm{AR}, 6 \mathrm{BF}$, and $6 \mathrm{BR}$ are as stated in reference $3 .{ }^{\ddagger} Y$, yes; $N$, No. Mutations were initially detected by direct DNA sequencing. ${ }^{\S}$ All mutations were detected on $12.5 \%$ polyacrylamide gels except this mutation at codon 218 which was only demonstrable on a $20 \%$ gel.

detection system (373A sequencer; Applied Biosystems, Foster City, CA). For the analysis of some PCR products, direct double-stranded DNA sequencing using the Sequenase (United States Biochemical Corp., Cleveland, $\mathrm{OH}$ ) protocol was performed as described previously (27). DNA sequence abnormalities in the probands, which were confirmed either by restriction endonuclease analysis or by hybridization to sequence-specific ${ }^{32} \mathrm{P}$-end labeled 19-mer oligonucleotides ( SSO) as described previously $(23,27)$, were demonstrated to cosegregate with the disorder and to be absent in the DNA obtained from 55 unrelated individuals. Primers 7FF and 6BR were also used to investigate the conservation of the sixth transmembrane domain of the $\mathrm{CaR}$ in the nine species: African green monkey, Aotus monkey, marmoset, pig, horse, cow, rabbit, hamster, and mouse, using the conditions described above, with the exception of the annealing temperature which was reduced to $60^{\circ} \mathrm{C}$ for rodent DNA.

Single-stranded conformational polymorphism (SSCP) analysis. Genomic DNA from a proband and 10 unrelated normal individuals was used with appropriate primers (Fig. 2) for PCR amplification, as described above, and the PCR products were analyzed for SSCP using the Phast electrophoresis system (Pharmacia LKB, Uppsala, Sweden) as follows. A 3- $\mu 1$ aliquot of the PCR product was diluted with $6 \mu \mathrm{l}$ of $66 \%$ formamide, denatured at $95^{\circ} \mathrm{C}$ for $5 \mathrm{~min}$, cooled on ice for $3 \mathrm{~min}$, and $2 \mu \mathrm{l}$ was loaded onto a precast 12.5 or $20 \%$ polyacrylamide gel with natural buffer strips (Pharmacia LKB), which had been precooled to the required electrophoresis temperature. Gel electrophoresis was performed at either 10,15 , or $20^{\circ} \mathrm{C}$ and at $210-350 \mathrm{Vh}$ depending upon the size of the fragment. The gel was fixed in: $10 \%$ ethanoic acid and $50 \%$ ethanol for $10 \mathrm{~min}$; $5 \%$ glutaraldehyde for $5 \mathrm{~min}$; $5 \%$ ethanoic acid and $10 \%$ ethanol for $10 \mathrm{~min}$. Silver staining with $0.025 \mathrm{M}$ aqueous silver nitrate for 10 min revealed the SSCPs which were scored by two independent observers (D. Trump and R. V. Thakker), who were blinded to the identity of the samples.

\section{Results}

Mutations in FBH families. Segregation analysis in the nine FBH families (Fig. 1) did not exclude an association between FBH and the haplotypes obtained with the six microsatellite polymorphic loci from chromosome $3 \mathrm{q} 21-\mathrm{q} 24$, and an analysis of the Southern blots obtained with the two intragenic DNA probes from exons 4 and 7 did not reveal any deletion or re- arrangement of the $\mathrm{CaR}$ gene. DNA sequence analysis was therefore performed, and an investigation of the entire 3,234bp coding sequence of the CaR gene from each of the nine probands revealed the presence of six novel heterozygous point mutations (Table III). Thus, five of the six mutations were missense mutations and one was a nonsense mutation, and all occurred within the exons that encode either the extracellular or the transmembrane domains of the CaR (Fig. 2), and none occurred in the $3^{\prime}$ segment of exon 7 that encodes the intracellular tail of the receptor. The occurrence of each of these mutations in the six probands of families 11/91, 16/94, 19/89, 23/ 92, 02/94, and 04/89 (Fig. 1) was confirmed either by SSO hybridization analysis (Fig. 3 ) or by restriction enzyme analysis (Fig. 4) to cosegregate with FBH. In addition, the absence of these DNA sequence abnormalities in 110 alleles from 55 unrelated normal individuals established that these abnormalities were mutations and not functionally neutral polymorphisms which would be expected to occur in $>1 \%$ of the population.

Table III. Mutations Detected in FBH Kindreds and NHPT Patients

\begin{tabular}{lrrlll}
\hline \multicolumn{1}{c}{ Family } & Exon & Codon & Base change & Amino acid & RE/SSO* \\
\hline FBH kindreds & & & & & \\
$11 / 91$ & 2 & 55 & CCG $\rightarrow$ CTG & Pro $\rightarrow$ Leu & HaeIII \\
$16 / 94$ & 4 & 218 & TAT $\rightarrow$ TCT & Tyr $\rightarrow$ Ser & HinfI \\
$19 / 89$ & 7 & 607 & TCG $\rightarrow$ TAG & Ser $\rightarrow$ Stop & SfcI \\
$23 / 92$ & 7 & 670 & GGG $\rightarrow$ AGG & Gly $\rightarrow$ Arg & SSO \\
$02 / 94$ & 7 & 680 & CGC $\rightarrow$ TGC & Arg $\rightarrow$ Cys & HhaI \\
$04 / 89$ & 7 & 817 & GTC $\rightarrow$ ATC & Val $\rightarrow$ Ile & SSO \\
NHPT probands & & & & & \\
$08 / 93$ & 4 & 227 & CGA $\rightarrow$ CTA & Arg $\rightarrow$ Leu & BfaI \\
$08 / 94$ & 7 & 582 & TGT $\rightarrow$ TAT & Cys $\rightarrow$ Tyr & AlwNI \\
$18 / 92$ & 7 & 747 & CCC $\rightarrow$ T-C & Frameshift & HhaI \\
& & & & & \\
\hline
\end{tabular}

* Analysis by restriction enzymes $(R E)$ or by SSO hybridization. 
$a$

Codon

668

669

670

671

Wild Type (WT)

Mutant (m)

TTC ATC

$\mathbf{A}_{\mathrm{AG}}$

GAG

Family 23/92

$b$

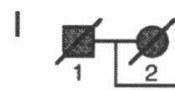

II

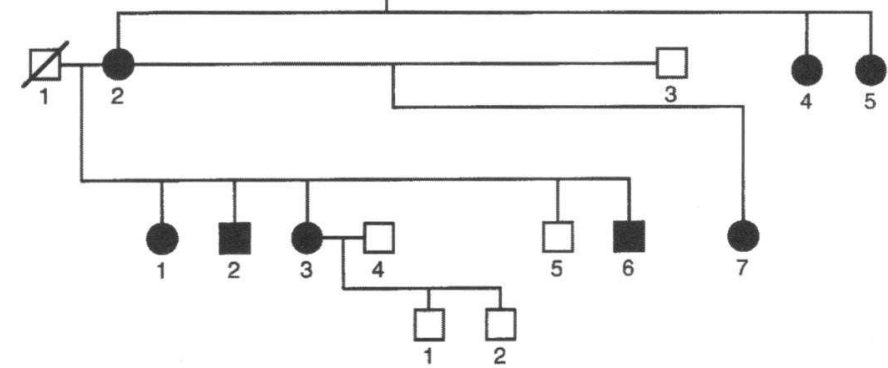

$\begin{array}{lll}\mathrm{N}_{1} & \mathrm{~N}_{2} & \mathrm{~N}_{3}\end{array}$
Figure 3. Missense mutation in exon 7 of the CaR gene in family 23/92 affected with FBH. Analysis of the DNA sequence chromatogram of individual II-2 from family $23 / 92$ revealed a $\mathrm{G}$ to $\mathrm{A}$ transition at codon $670(a)$ which would result in the alteration from a glycine (G) to an arginine (R). The cosegregation of this mutation (G670R) in family $23 / 92$ and its absence from 55 unrelated normal individuals $\left(\mathrm{N}_{1-3}\right.$ shown $)$ were demonstrated by SSO hybridization analysis $(b)$ as it was not associated with an alteration of a restriction enzyme site. Thus, the three unrelated normal individuals $\left(\mathbf{N}_{1-3}\right)$ and the unaffected individuals IV-1, IV-2, III-5, and II-3 were found to have only the wild-type (WT) sequence (G670) and none of the mutant $(\mathrm{m}) \mathrm{se}$ quence (G670R), and were therefore homozygous for the wild-type sequence. However, all of the affected members have both the wild-type and the mutant sequence and this heterozygosity illustrates the dominant nature of the mutation. A similar analysis using SSO was used to demonstrate cosegregation (data not shown) of the V817I mutation (Table III) found in family $04 / 89$ (Fig. 1).
Thus, six of the nine FBH families were found to have mutations in the CaR gene, located at chromosome 3q21-q24, and our findings of a nonsense mutation demonstrate further the etiological role of the CaR gene in FBH.

Four of the five missense CaR mutations, which also suggested an important role for this gene in FBH, predicted the following structurally significant amino acid changes (Table II): a proline at codon 55 to leucine within the amino-terminal exon 2 (P55L); a tyrosine to a serine at codon 218 in exon 4 (Y218S); a neutral glycine to a charged arginine at codon 670 within the second transmembrane domain in exon 7 (G670R); and a charged arginine to a cysteine at codon 680 within the first extracellular loop in exon 7 (R680C). The fifth missense mutation was a GTC $\rightarrow$ ATC transition at codon 817 in family $04 / 89$ (Fig. 1) and this would result in the substitution of a valine residue by an isoleucine (Table III) within the sixth transmembrane domain in exon 7 (V817I). This substitution is conservative as valine and isoleucine are both hydrophobic, nonpolar aliphatic amino acids differing structurally only by one methylene group. The significance of this alteration was therefore further investigated by a comparative analysis of the predicted amino acid sequence of the sixth transmembrane domain in 10 mammalian species. This revealed a $100 \%$ conservation of all the 22 amino acids of the sixth transmembrane domain, including the Val 817 residue, and indicated that the V817I substitution was likely to be of functional significance.

Mutations in NHPT patients. Examination of the 3,234-bp coding region of the $\mathrm{CaR}$ gene in the three unrelated children with NHPT (Fig. 1) showed different de novo heterozygous missense mutations $\mathrm{R} 227 \mathrm{~L}$ and $\mathrm{C} 582 \mathrm{Y}$ in the children from families 08/93 and 08/94 (Fig. 5), respectively, and a combined homozygous $\mathrm{C}$ to $\mathrm{T}$ transition and a 1-bp deletion involving codon 747 in the child from family $18 / 92$ (Fig. 6). Nonpaternity was excluded for each of these children by the demonstration of shared alleles for each of the five highly polymorphic loci D3S1303, D3S1267, D11S533, D13S260, and Rb1.20 (25). Our finding of the heterozygous missense mutations in two children with NHPT is of interest since previously this disorder was reported to be associated with homozygous mutations only, with the heterozygous mutations being associated with the asymptomatic disorder FBH (3-5). Our results obtained from these children and their families demonstrate that heterozygous mutations of the $\mathrm{CaR}$ gene may arise de novo and can be associated with NHPT. The analysis of the NHPT child (II-1) from family $18 / 92$ revealed further interesting findings. The unusual homozygous mutation at codon 747 was confirmed by direct double-stranded DNA sequencing (Fig. 6), and the mutation which predicted a frameshift gave rise to a 28-amino acid stretch of missense peptide in which a stop signal (TGA) occurred at codon 776 . This mutation at codon 747 was associated with the loss of an HhaI site and was used to confirm that the proband II-1 was homozygous for the mutation and that his normocalcemic parents were heterozygous (Fig. 6). Both the parents in family $18 / 92$ were observed to have the same unusual 
Wild Type (WT)

Mutant (m)

TCA

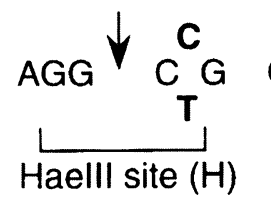

GAG

$N_{1} N_{2} N_{3} \cup M$

Family $11 / 91$

$b$

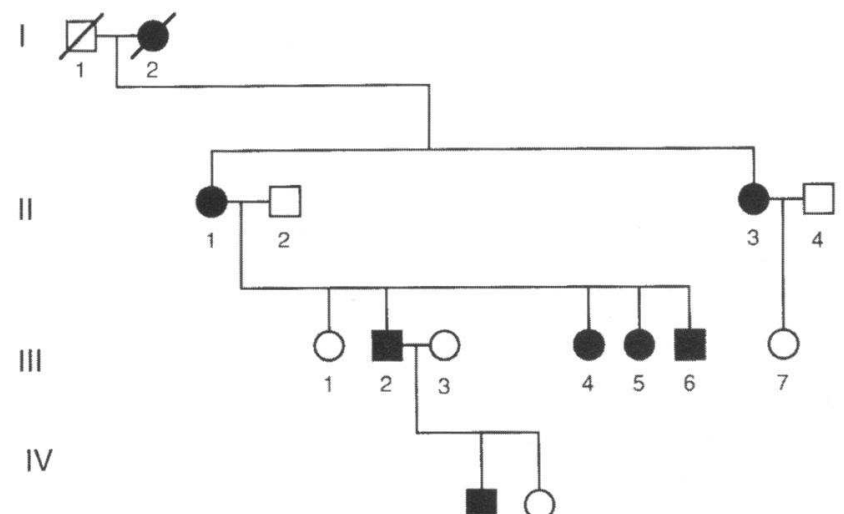

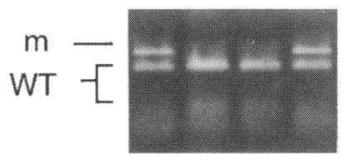

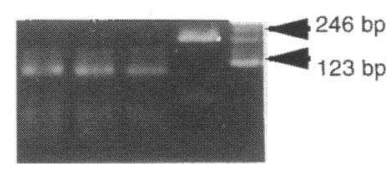

c

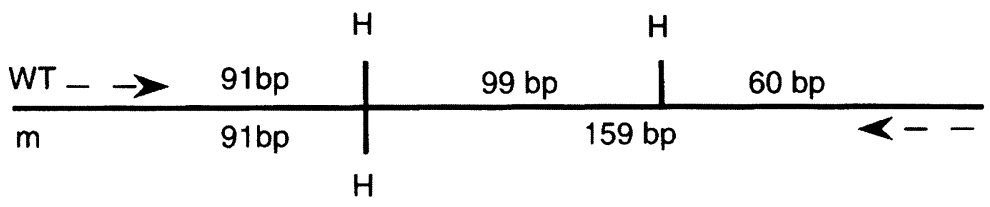

Figure 4. Detection of mutation in exon 2 in family $11 / 91$ by restriction enzyme analysis. DNA sequence analysis of individual II-1 from family 11/91 (Fig. 1) revealed a $\mathrm{C}$ to $\mathrm{T}$ transition at codon $55(a)$, thus altering the wild-type (WT) sequence, CCG, encoding a proline $(\mathrm{P})$ to the mutant sequence, CTG, encoding a leucine (L). This missense mutation also resulted in the loss of the wildtype HaelII restriction enzyme (H) site (GG/CC). PCR amplification and HaeIII digestion would result in two products of 99 and $60 \mathrm{bp}$ from the normal sequence but an additional band of $159 \mathrm{bp}$ would be expected from the mutant sequence as is illustrated in the restriction map in $c$. Cosegregation of this P55L mutation and its heterozygosity in members affected with FBH was demonstrated $(b)$, and the absence of this P55L mutation in 110 alleles from 55 unrelated normocalcemic individuals $\left(\mathrm{N}_{1-3}\right.$ shown) indicates that it is not a common DNA sequence polymorphism. Similar restriction enzyme analysis was used to demonstrate cosegregation of the Y218S,

S607stop, and R680C mutations (Table III) with FBH found in families 16/94, 19/89, and 02/94 (Fig. 1). mutation at codon 747 , and this indicated that they are likely to have shared a common ancestor, although both parents denied consanguinity. Thus, our findings in family $18 / 92$ revealed that heterozygote mutations of the $\mathrm{CaR}$ gene are not always associated with demonstrable hypercalcemia but that individuals with such heterozygote $\mathrm{CaR}$ mutations may be normocalcemic.

Mutational detection by SSCP analysis. Eight of the nine point mutations found by direct DNA sequence analysis were correctly identified by SSCP analysis and the detection of three of these in exon 7 is demonstrated in Fig. 7. SSCP analysis of the smaller PCR fragments of $<300 \mathrm{bp}$, such as those encompassing exon 2 (primers $1 \mathrm{~F}$ to $1 \mathrm{R}$ ) and the $5^{\prime}$ portion of exon 7 (primers 7GF to 6AR), readily detected the point mutations. However, SSCP analysis of the larger PCR fragments $(>350$ bp) such as those from primers $6 \mathrm{BF}$ to $7 \mathrm{ER}$ required the conditions to be optimized before some of the mutations could be identified (Fig. 7). The details of these conditions for SSCP analysis for each of the PCR products are shown along with the primer sequences in Table II. Using these conditions only one mutation (V817I) could not be detected by SSCP analysis, and this may be due to the large size of this PCR product which may give the single DNA strand greater stability in the gel in a single structural conformation (28). Our SSCP analysis of $>200$ individual PCR products of the CaR gene did not consis- tently detect any other abnormal bands, thereby indicating an absence of false-positive results. Thus, SSCP analysis proved to be a sensitive and reliable method in the detection of eight of these nine mutations.

\section{Discussion}

Our results have identified nine novel mutations of the CaR gene in six families with FBH and three children with NHPT and these mutations are of help in speculating upon the structurefunction relationships of the $\mathrm{CaR}$. The human $\mathrm{CaR}$ which consists of 1,078 amino acids (Fig. 2) is predicted to have: a large 612 amino acid extracellular, presumably calcium-binding domain; seven transmembrane domains with three intracellular and three extracellular loops; and an intracellular tail $(1-3,29)$. The amino acid sequence of the $\mathrm{CaR}$ is highly conserved and the human $\mathrm{CaR}$ shares $93 \%$ overall amino acid identity with both the bovine and rat CaRs $(1-3,29,30)$. This conservation between the human and bovine sequences is more marked within the extracellular and the transmembrane domains each of which shares 96 and $98 \%$ amino acid identity, respectively $(1,2)$, than within the intracellular tail which shares only $82 \%$ amino acid identity. Thus, this comparative analysis suggests that the structure of the intracellular domain is less critical to normal $\mathrm{CaR}$ 
a Codon

Wild Type (WT)

Mutant ( $m$ )

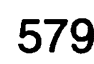

579

580

581

582

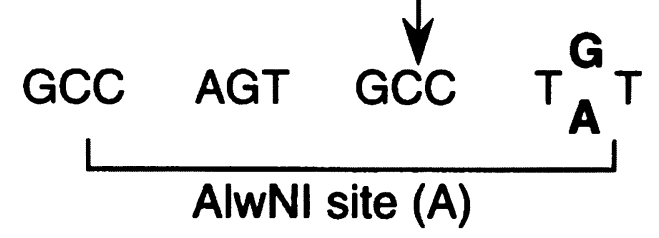

b Family $08 / 94$

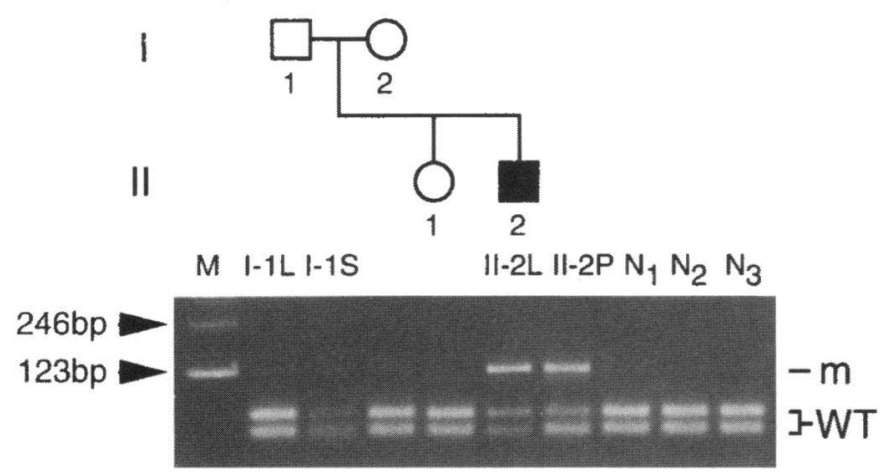

c

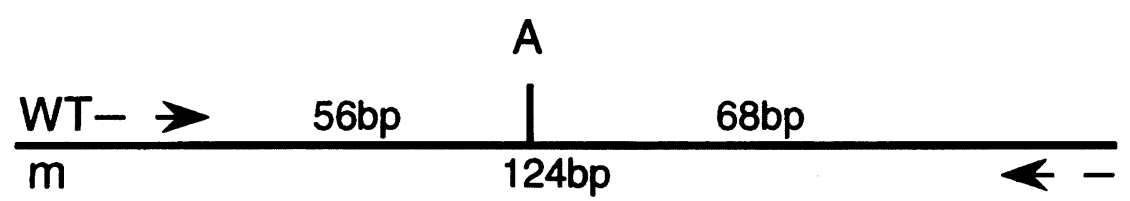

Figure 5. De novo heterozygous missense mutation of the $\mathrm{CaR}$ gene in NHPT. DNA sequence analysis of the child II-2 with NHPT from family $08 / 94$ revealed a $\mathrm{G}$ to $\mathrm{A}$ transition at codon 582. The wild-type (WT) DNA sequence at codon 582 is TGT coding for a cysteine (C) residue whereas the mutant sequence $(\mathrm{m})$ is TAT encoding a tyrosine $(\mathrm{Y})$ residue $(a)$. This missense mutation, C582Y, resulted in the loss of an AlwNI site $(A)$, which facilitated its detection in family $08 /$ $94(b)$. The restriction map (c) of the PCR product shows that the wild-type ( $W T$ ) DNA sequence, which has one AlwNI site, is associated with cleaved PCR products of 56 and $68 \mathrm{bp}$, whereas the mutant $(m)$ which has lost the AlwNI site is associated with a PCR product of $124 \mathrm{bp}$. Analysis of family $08 / 94(b)$ revealed that the affected child (II-2) was heterozygous and that his normocalcemic parents (I-1 and I-2) and sister (II-1) were homozygous for the wild-type alleles. Furthermore, an analysis of the leukocyte (L) and hyperplastic parathyroid tissue (P) DNA revealed that the parathyroid tissue was also heterozygous for the C582Y mutation and was not associated with an allelic loss that would indicate a role for the CaR as a tumor suppressor gene. In addition, an analysis of DNA from the father's semen (I-1S) revealed an absence of the mutation, thereby indicating that he was unlikely to have germ line mosaicism. Analysis of 55 unrelated normocalcemic individuals $\left(\mathrm{N}_{1-3}\right.$ shown $)$ revealed an absence of the $\mathrm{C} 582 \mathrm{Y}$ mutation, thereby confirming that it is not a common DNA sequence polymorphism. Thus, NHPT is associated with a heterozygous de novo mutation in this family. A similar analysis in family 08/93 demonstrated that a de novo heterozygous R227L mutation (Table III) was also associated with NHPT.

function than that of the highly conserved extracellular and transmembrane domains, and the report of three functionally neutral amino acid polymorphisms within the intracellular tail (31) and our nine hypercalcemia-associated mutations which were either within the extracellular or transmembrane domains of the receptor support this prediction.

Our nine mutations of the CaR gene (Table III) may result in a decrease of the biological activity of the $\mathrm{CaR}$, by producing either an unstable $\mathrm{CaR}$ transcript or protein that is not expressed at the cell surface or a structural change disrupting the function of the expressed CaR protein. For example, the S607 stop (Table III) and P747 frame-shift mutations (Fig. 6) predict the occurrence of truncated proteins of 606 and 775 amino acids, respectively and, if expressed, each would likely result in a nonfunctional $\mathrm{CaR}$. The remaining seven $\mathrm{CaR}$ mutations are all missense substitutions and these, together with the 11 previously reported missense mutations $(3,5,31)$, all involve structurally significant amino acid changes at residues that are conserved between human, rat, and bovine CaRs $(1,2,30)$. For instance, the codon Y218S and R227L mutations (Table III) occur within an area of the receptor proposed to be important for ligand-binding (1) and the $\mathrm{C} 582 \mathrm{Y}$ mutation occurs at one of the 20 conserved cysteine residues that may maintain the secondary structure of the CaR $(1,30)$. The V817I mutation (Table III) involves 1 of the 22 amino acids that are all conserved in the sixth transmembrane domain of the $\mathrm{CaR}$ and this indicates that this mutation is also likely to be of importance in the etiology of FBH. The finding of heterozygous loss of function mutations in both FBH and NHPT patients suggests that these $\mathrm{CaR}$ gene mutations may act in a dominant-negative fashion (32) to disrupt the functioning of the intact wild-type CaR. This may occur by protein-protein interactions either at a subcellular level as has been documented for other $G$ protein-coupled receptors (33) or at the cell surface by the formation of as yet uncharacterized dimeric or multimeric receptor complexes (34). Another explanation for this heterozygous phenotype is that the setting of the extracellular calcium level is critically dependent simply upon the number of functional $\mathrm{CaRs}$ upon the cell surface (3) or that the mutant receptors compete for occupancy of the $G$ protein. Further studies of the $\mathrm{CaR}$ mutations will help to define these possibilities.

Mutations of the CaR gene were not found in three of the FBH families (11/94, 18/94, and 23/91), and linkage studies in these could not exclude the CaR locus (35). In addition, we could not exclude mutations involving the promoter regions or 


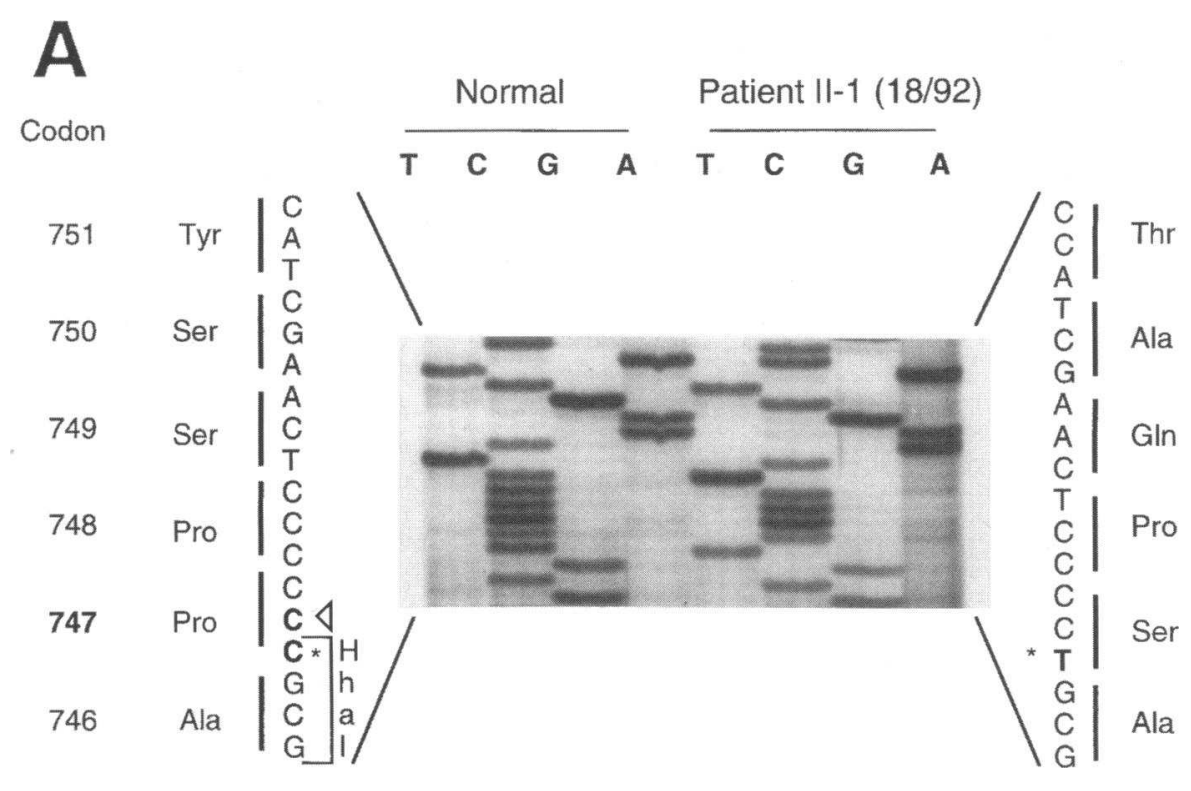

B

a. Codon 746 747 748 749

Wild Type (WT)

Mutant ( $m$ )

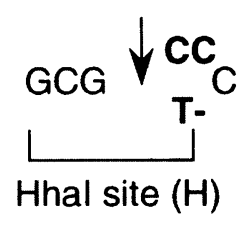

CCC TCA

$b$. Family $18 / 92$

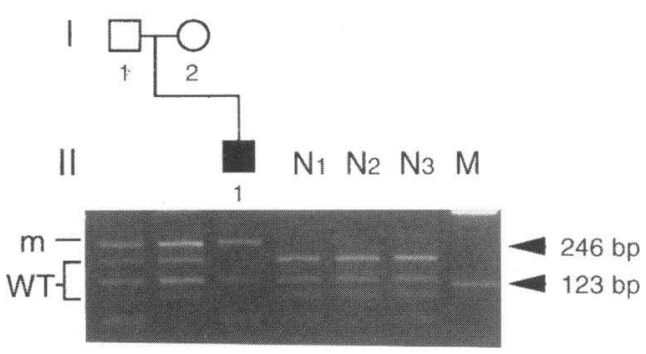

c.

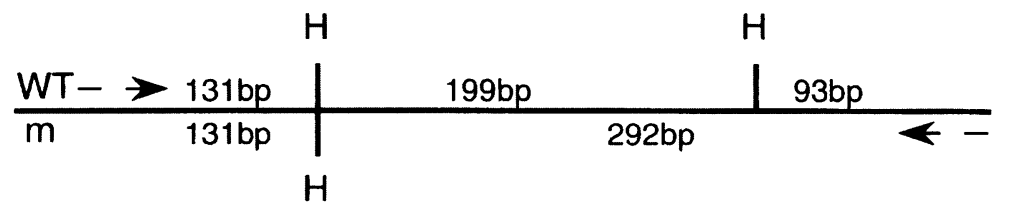

Figure 6. Association of normocalcemia with a heterozygous mutation and of NHPT with a homozygous mutation of the $\mathrm{CaR}$ gene in family $18 / 92$. The DNA sequence autoradiograph from codons 746 to 751 of the NHPT child (II-1) from family $18 / 92$ is shown on the right-hand side of $A$ and is compared with one obtained from a normal individual on the left-hand side. The patient's DNA sequence reveals a $\mathrm{C}$ to $\mathrm{T}$ transition (*) at the first position of codon 747 together with a 1-bp deletion at the second position of this codon $(\triangle)$. The predicted amino acid sequences for the normal and patient's DNA sequence are shown adjacent, and the missense mutation has resulted in the substitution of a proline for a serine (P747S) and the deletion has caused a frame-shift which has resulted in a missense peptide which continues to codon 775 before a stop codon (TGA) is encountered in the new frame. The $\mathrm{C}$ to $\mathrm{T}$ transition results in the loss of an HhaI restriction site (GCG/C) from the normal (wild-type) sequence $(B$, panel $a)$ and this has facilitated the detection of this mutation in the parents (I-1 and I-2; panel $b$ ). The mutant PCR product is 292 bp whereas the wild-type (WT) products are 199 and $93 \mathrm{bp}$ (panel $c$ ). The child (II-1) was confirmed to be homozygous for the mutation but both parents, who were normocalcemic, were heterozygous for the mutation. These DNA sequence abnormalities of codon 747 were not observed in 55 unrelated normocalcemic individuals. Thus, in family $18 / 92$, the homozygous mutation at codon 747 is associated with NHPT and the heterozygous mutation is associated with normocalcemia in both father (I-1) and mother (I-2) (Table I). three of the intron/exon splice sites of the $\mathrm{CaR}$ gene in these families. However, the genetic heterogeneity of FBH is well established with one FBH locus linked to chromosome 19p13 (36) and another locus not linked to either 3q21-q24 or 19p13 $(25,37)$. The three FBH families, 11/94, 18/94, and 23/91, were not suitable for extensive linkage studies to exclude these chromosomal regions, and the future cloning of the genes causing these other forms of $\mathrm{FBH}$ and the elucidation of the pro- moter and remaining splice sites of the $\mathrm{CaR}$ gene will help to characterize the mutations in our FBH families 11/94, 18/94, and $23 / 91$, and those reported previously (5).

Our finding of two de novo heterozygous missense mutations occurring in children with sporadic NHPT provides strong support for the etiological role of $\mathrm{CaR}$ gene mutations in this disorder. However, previous linkage studies (38) and mutational analysis (3-5) have found that NHPT occurring in the 


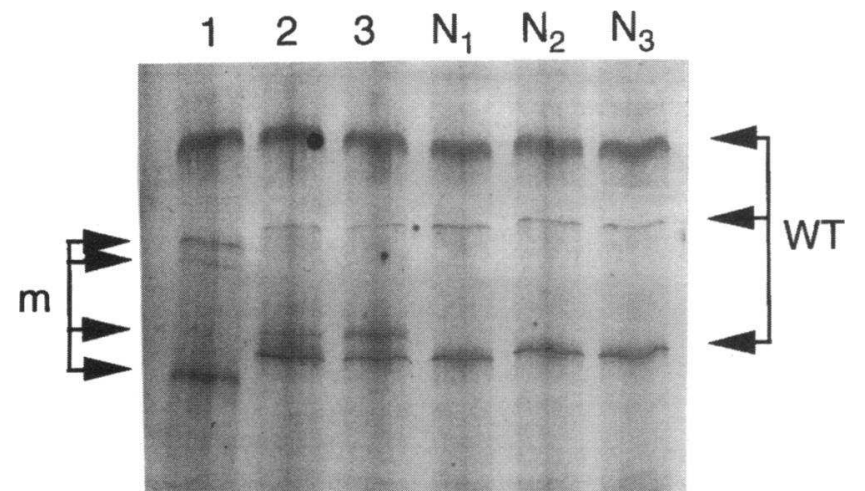

Figure 7. Detection of three mutations in exon7 by SSCP. The results of SSCP analysis $\left(350 \mathrm{Vh}\right.$ at $15^{\circ} \mathrm{C}$ ) silver staining of a $12.5 \%$ polyacrylamide gel revealed four mutant bands $(m)$ which differed from the three wild-type $(W T)$ bands. Lanes $1-3$ demonstrate the $C$ to $T$ transition/ frame-shift mutation of family 18/92 involving codon 747 (Fig. 6), the R680C mutation of family $02 / 94$, and the G670R mutation of family 23/92 (Fig. 3), respectively. These PCR products were derived using the primers $6 \mathrm{BF}$ and $7 \mathrm{ER}$ (Table II), and all three mutations found by DNA sequencing of this PCR product were detectable by SSCP analysis using the conditions described in Table II.

context of an FBH family is associated with a homozygous affected haplotype or homozygous missense mutations. These genetic differences may be reflected in the clinical heterogeneity of NHPT in which some children may have a severe disorder with a high mortality $(10,12-14)$ and other children may have a milder disorder with a self-limiting course $(11,14-18)$. Thus, in the NHPT children of families $08 / 93$ and $08 / 94$ (Fig. 1) who had heterozygous mutations, the elevations of serum calcium (Table I) were observed to be modest when compared with those observed in the NHPT child of family 18/92, who had a homozygous mutation, and whose serum calcium was similar to that observed in some other NHPT children (10-14, $17,18)$. This mild neonatal expression in the NHPT children with de novo heterozygous $\mathrm{CaR}$ mutations may also be comparable with the mild NHPT phenotype that has been observed in the heterozygous FBH children who have inherited a paternal mutation and are born to normocalcemic mothers $(15,16)$. In this situation the prevailing maternal normocalcemia may cause varying degrees of fetal parathyroid hyperplasia, depending upon the severity of the underlying set-point abnormality (11, 14), and this together with the skeletal response to PTH may determine the severity of the neonatal hypercalcemia.

FBH may be difficult to differentiate from mild primary hyperparathyroidism on the basis of PTH estimation and urinary calcium excretion alone, as illustrated by families $04 / 89$ and 11/91 (Table I). In addition, family histories and investigations from small kindreds (e.g., family 19/89, Fig. 1) may not reveal the presence of $\mathrm{FBH}$, and the occurrence of familial primary hyperparathyroidism, either as an isolated endocrinopathy or as part of the multiple endocrine neoplasia type 1 (MEN1) syndrome (39) may also make the distinction between FBH and these disorders difficult $(7-9,11,14,19)$. The identification of $\mathrm{CaR}$ mutations in these instances may be of help, as illustrated by family $02 / 94$ ( Fig. 1). However, the mutational diversity within the $3,234 \mathrm{bp}$ of the $\mathrm{CaR}$ gene $(3-5,31)$ makes mutational screening for FBH by a direct DNA sequencing approach in patients with hypercalcemia time-consuming. We have therefore explored the use of the SSCP technique for the more rapid screening of $\mathrm{CaR}$ mutations. Our results demonstrated that SSCP was a useful, sensitive, and specific method that was successful in the detection of $>85 \%$ of the CaR mutations in our families. Although the sensitivity of SSCP is dependent upon the size of the DNA fragment (28), we were able to identify three mutations within a 423-bp PCR product by using optimized conditions (Table II). Thus, our findings indicate that mutational analysis using SSCP may be of help in supplementing the clinical evaluation of asymptomatic hypercalcemic patients who may have equivocal urinary calcium excretion studies or in whom a family history is difficult to elicit.

\section{Acknowledgments}

We are grateful to Drs. S. Ball, J. Morrison, and A. Soutar for helpful discussions and to Dr. R. A. Furlong for technical details.

We are grateful to the Medical Research Council (S. H. S. Pearce, D. Trump, C. Wooding, and R. V. Thakker), and to the Shriners Hospitals for Crippled Children (grant 15958 to M. P. Whyte) for support. S. H. S. Pearce, D. Trump, and S. L. Chew are Medical Research Council Training Fellows.

\section{References}

1. Brown, E. M., G. Gamba, D. Riccardi, M. Lombardi, R. Butters, O. Kifor, A. Sun, M. A. Hediger, J. Lytton, and S. C. Hebert. 1993. Cloning and characterization of an extracellular $\mathrm{Ca}^{2+}$-sensing receptor from bovine parathyroid. Nature (Lond.). 366:575-580.

2. Pearce, S. H. S., and R. V. Thakker. 1996. Comparative analysis of the bovine and human calcium-sensing receptors. In The Comparative Endocrinology of Calcium Regulation. C. Dacke, J. Danks, I. Caple, and G. Flick, editors. J. Endocrinol Ltd, Bristol, United Kingdom. In press.

3. Pollak, M. R., E. M. Brown, Y. W. H. Chou, S. C. Hebert, S. J. Marx, B. Steinmann, T. Levi, C. E. Seidman, and J. G. Seidman. 1993. Mutations in the human $\mathrm{Ca}^{2+}$-sensing receptor gene cause familial hypocalciuric hypercalcemia and neonatal severe hyperparathyroidism. Cell. 75:1297-1303.

4. Janicic, N., Z. Pausova, D. E. C. Cole, and G. N. Hendy. 1995. Insertion of an Alu sequence in the $\mathrm{Ca}^{2+}$-sensing receptor gene in familial hypocalciuric hypercalcemia and neonatal severe hyperparathyroidism. Am. J. Hum. Genet. $56: 880-886$.

5. Chou, Y. H., M. R. Pollak, M. L. Brandi, G. Toss, H. Arnqvist, A. B. Atkinson, S. E. Papapoulos, S. Marx, E. M. Brown, J. G. Seidman, and C. E. Seidman. 1995. Mutations in the human $\mathrm{Ca}^{2+}$-sensing-receptor gene that cause familial hypocalciuric hypercalcemia. Am. J. Hum. Genet. 56:1075-1079.

6. Pollak, M. R., E. M. Brown, H. L. Estep, P. N. McLaine, O. Kifor, J. Park, S. C. Hebert, C. E. Seidman, and J. G. Seidman. 1994. Autosomal dominant hypocalcaemia caused by a $\mathrm{Ca}^{2+}$-sensing receptor mutation. Nat. Genet. 8:303307.

7. Marx, S. J., M. F. Attie, M. A. Levine, A. M. Spiegel, R. W. Downs, and R. D. Lasker. 1981. The hypocalciuric or benign variant of familial hypercalcemia: clinical and biochemical features in fifteen kindreds. Medicine (Baltimore). 60:397-412.

8. Law, W. M., and H. Heath. 1985. Familial benign hypercalcemia (hypocalciuric hypercalcemia). Clinical and pathogenetic studies in 21 families. Ann. Intern. Med. 102:511-519.

9. Paterson, C. R., and A. Gunn. 1981. Familial benign hypercalcaemia. Lancet. 2:61-63.

10. Sopwith, A. M., C. Burns, D. B. Grant, G. W. Taylor, E. Wolf, and G. M. Besser. 1984. Familial hypocalciuric hypercalcaemia: association with neonatal primary hyperparathyroidism, and possible linkage with HLA haplotype. Clin. Endocrinol. 21:57-64.

11. Heath, H., III. 1989. Familial benign (hypocalciuric) hypercalcemia, a troublesome mimic of mild primary hyperparathyroidism. Endocrinol. Metab. Clin. North Am. 18:723-740.

12. Spiegel, A. M., H. E. Harrison, S. J. Marx, E. M. Brown, and G. D Aurbach. 1977. Neonatal primary hyperparathyroidism with autosomal dominant inheritance. J. Pediatr. 90:269-272.

13. Marx, S. J., M. F. Attie, A. M. Spiegel, M. A. Levine, R. D. Lasker, and M. Fox. 1982. An association between neonatal severe primary hyperparathyroidism and familial hypocalciuric hypercalcemia in three kindreds. N. Engl. J. Med. 306:257-264.

14. Heath, D. A. 1994. Familial hypocalciuric hypercalcemia. In The Parathy- 
roids. J. P. Bilezikian, M. A Levine, and R. Marcus, editors. Raven Press, New York. 699-710

15. Page, L. A., and J. E. Haddow. 1987. Self limited neonatal hyperparathyroidism in familial hypocalciuric hypercalcaemia. J. Pediatr. 111:261-264.

16. Wilkinson, H., and J. James. 1993. Self limiting neonatal primary hyperparathyroidism associated with familial hypocalciuric hypercalcaemia. Arch. Dis. Child. 69:319-321.

17. Nishiyama, S., S. Tomoeda, F. Inoue, T. Ohta, and I. Matsuda. 1990. Selflimited familial hyperparathyroidism associated with hypercalciuria and renal tubular acidosis in three siblings. Pediatrics. 86:421-427.

18. Meeran, K., M. Husain, M. Puccini, H. Scott, C. Dionisi-Vici, D. R. Harvey, J. Lynn, and R. V. Thakker. 1994. Neonatal primary hyperparathyroidism masked by vitamin D deficiency. Clin. Endocrinol. 41:531-534.

19. Marx, S. J., J. L. Stock, M. F. Attie, R. W. Downs, D. G. Gardner, E. M. Brown, A. M. Spiegel, J. L. Doppman, and M. F. Brennan. 1980. Familial hypocalciuric hypercalcemia: recognition amongst patients referred after unsuccessful parathyroid exploration. Ann. Intern. Med. 92:351-356.

20. Almahroos, G. M., K. Docherty, J. A. Fletcher, T. Webb, and D. A. Heath 1987. Studies of the parathyroid hormone gene in normal subjects, and in subjects with primary hyperparathyroidism and familial benign hypercalcaemia. J. Endocrinol. 115:183-186.

21. Mackintosh, P., G. Almahroos, and D. A. Heath. 1989. HLA linkage with familial vesicoureteral reflux and familial pelvi-ureteric junction obstruction Tissue Antigens. 34:185-189.

22. Dezateux, C. A., J. C. Hyde, H. M. C. V. Hoey, J. L. H. O'Riordan, L. Spitz, G. W. Taylor, and D. B. Grant. 1984. Neonatal hyperparathyroidism. Eur. J. Pediatr. 142:135-136.

23. Thakker, R. V., M. A. Pook, C. Wooding, M. Boscaro, M. Scanarini, and R. N. Clayton. 1993. Association of somatotrophinomas with loss of alleles on chromosome 11 and with gsp mutations. J. Clin. Invest. 91:2815-2821.

24. Thakker, R. V., K. E. Davies, M. P. Whyte, C. Wooding, and J. L. H. O'Riordan. 1990. Mapping the gene causing X-linked recessive idiopathic hypoparathyroidism to Xq26-Xq27 by linkage studies. J. Clin. Invest. 86:40-45.

25. Trump, D., M. P. Whyte, C. Wooding, J. T. Pang, S. H. S. Pearce, D. B. Kocher, and R. V. Thakker. 1995. Linkage studies in a kindred from Oklahoma, with familial benign (hypocalciuric) hypercalcaemia (FBH) and developmenta elevations in serum parathyroid hormone levels, indicate a third locus for FBH. Hum. Genet. 96:183-187.

26. Scheinman, S. J., M. A. Pook, C. Wooding, J. T. Pang, P. A. Frymoyer, and R. V. Thakker. 1993. Mapping the gene causing X-linked recessive nephrolithiasis to Xp11.22 by linkage studies. J. Clin. Invest. 91:2351-2357.

27. Parkinson, D., and R. V. Thakker. 1992. A donor splice site mutation in the parathyroid hormone gene is associated with autosomal recessive hypoparathyroidism. Nat. Genet. 1:149-152.

28. Grompe, M. 1993. The rapid detection of unknown mutations in nucleic acids. Nat. Genet. 5:111-117.

29. Garrett, J. E., I. V. Capuano, L. G. Hammerland, B. C. P. Hung, E. M. Brown, S. C. Hebert, E. F. Nemeth, and F. Fuller. 1995. Molecular cloning and functional expression of human parathyroid calcium receptor cDNAs. J. Biol. Chem. 270:12919-12925.

30. Riccardi, D. J. Park, W.-S. Lee, G. Gamba, E. M. Brown, and S. C. Hebert. 1995. Cloning and functional expression of a rat kidney extracellular calcium/polyvalent cation-sensing receptor. Proc. Natl. Acad. Sci. USA. 92:131135.

31. Heath, H., III, S. Odelberg, D. Brown, V. M. Hill, M. Robertson, C. E. Jackson, B. T. Teh, N. Hayward, C. Larsson, N. Buist, J. Garrett, and M. Leppert 1995. Mutations of calcium receptor $(\mathrm{CaR})$ exons 4 and 7 do not account for all cases of familial benign (hypocalciuric) hyrpercalcaemia (FBH). Bone. 16:140S

32. Herskowitz, I. 1987. Functional inactivation of genes by dominant negative mutations. Nature (Lond.). 329:219-222.

33. Maggio, R., Z. Vogel, and J. Wess. 1993. Coexpression studies with mutan muscarinic/adrenergic receptors provide evidence for intramolecular "cross-talk" between G protein-linked receptors. Proc. Natl. Acad. Sci. USA. 90:3103-3107.

34. Dejager, S., M. Mietus-Snyder, A. Friera, and R. E. Pitas. 1993. Dominant negative mutations of the scavenger receptor. Native receptor inactivation by expression of truncated variants. J. Clin. Invest. 92:894-902.

35. Chou, Y. H. W., E. M. Brown, T. Levi, G. Crowe, A. B. Atkinson, H. J. Arnqvist, G. G. Toss, G. E. Fuleihan, J. G. Seidman, and C. E. Seidman. 1992 The gene responsible for familial hypocalciuric hypercalcemia maps to chromosome $3 q$ in four unrelated families. Nat. Genet. 1:295-300.

36. Heath, H., C. E. Jackson, B. Otterud, and M. F. Leppert. 1993. Genetic linkage analysis in familial benign (hypocalciuric) hypercalcemia: evidence for locus heterogeneity. Am. J. Hum. Genet. 53:193-200.

37. McMurtry, C. T., F. W. Schranck, D. A. Walkenhorst, W. A. Murphy, D. B. Kocher, S. L. Teitelbaum, R. C. Rupich, and M. P. Whyte. 1992. Significant developmental elevation in serum parathyroid hormone levels in a large kindred with familial benign (hypocalciuric) hypercalcemia. Am. J. Med. 93:247-258.

38. Pollak, M. R., Y. H. W. Chou, S. J. Marx, B. Steinmann, D. E. C. Cole M. L. Brandi, S. E. Papapoulos, F. H. Menko, G. N. N. Hendy, E. M. Brown C. E. Seidman, and J. G. Seidman. 1994. Familial hypocalciuric hypercalcemia and neonatal severe hyperparathyroidism. Effects of mutant gene dosage on phenotype. J. Clin. Invest. 93:1108-1112.

39. Thakker, R. V. 1994. Multiple endocrine neoplasia type 1. In Endocrinology. 3rd edition. L. J. DeGroot, G. M. Besser, H. G. Burger, J. L. Jameson, D. L. Loriaux, J. C. Marshall, W. D. Odel, J. T. Potts, Jr., and A. H. Rubenstein, editors. W. B. Saunders Co., Philadelphia. 2815-2831. 